\title{
Galea and periosteum flap filled with bone fragments in rabbits ${ }^{1}$
}

\author{
Ryane Schmidt Brock, Fausto Viterbo ${ }^{\mathrm{II}}$, Guilherme Capel $^{\mathrm{III}}$, Maria Aparecida Custodio Domingues ${ }^{\mathrm{IV}}$, Eloísa Elena \\ Paschoalinotte $^{\mathrm{V}}$, Daniel LabbévI
}

IFellow Master degree, Postgraduate Program in General Surgery Basis, Medical School of Botucatu, UNESP, Sao Paulo-SP, Brazil. Intellectual and scientific content of the study, acquisition of data, manuscript writing.

IIPhD, Associate Professor and Head of Plastic and Reconstructive Surgery Division, Department of Surgery, Botucatu School of Medicine, UNESP, Sao Paulo-SP, Brazil. Conception, design, intellectual and scientific content of the study, interpretation of data, critical revision.

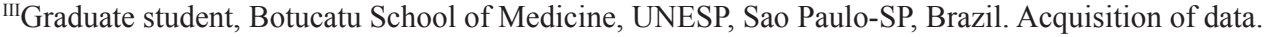

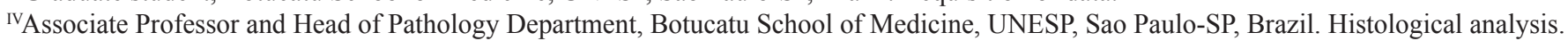

${ }^{v}$ Estatistical analyst, Member of the Research Support Group, Botucatu School of Medicine, UNESP, Sao Paulo-SP, Brazil. Statistical analysis.

${ }^{\mathrm{V}} \mathrm{MD}$, Plastic Surgeon, Caen University Hospital, Department of Plastic and Maxillo-Facial Surgery. Critical revision.

\begin{abstract}
PURPOSE: To study the bone viability of a vascularized galea and periosteum flap filled with bone fragments, as a substitute of the bone graft in facial reconstructive surgery.

METHODS: Forty rabbits were studied, and divided in two groups. One had a simple galea and periosteum flap done and the other had the same flap done and filled with bone fragments of the calvaria. The bone formation was evaluated by radiographies, macroscopic and microscopic analysis.
\end{abstract}

RESULTS: The bone neoformation in both groups with differences in bone morphology and structure especially at histological analysis. CONCLUSION: This study demonstrated osseous formation in both groups of galea and periosteum flaps, with and without bone fragments.

Key words: Bone. Skull. Surgical Flaps. Reconstruction. Grafts. Rabitts. 


\section{Introduction}

Facial osseous defects caused by tumor resection, congenital malformation or trauma need reconstruction to recover the functional aspects of these lesions, like speech, breath, swallow, and also the aesthetic aspect of these patients ${ }^{1-5}$.

Facial tumors that demand extensive resection and even adjuvant treatments like radiotherapy, lead to function deformities and social problems because of the deformed appearance. The radiotherapy, necessary to complete the cancer treatment, interferes at the fracture healing and remodeling because it stimulates apoptosis and affects the blood supply ${ }^{6,7}$.

Congenital malformations like Franceschetti, Crouzon and Goldenhar Syndromes, facial clefts or mandible hypoplasia are even important as they need osseous tissue to reconstruct the defects. These malformations interfere at the social development of these children ${ }^{8,9}$.

Traumas are other important and usual reason of facial defects. Many times, only fracture correction is not enough to treat these patients. Some of them can lose an extensive part of soft and osseous tissue that demands more specific reconstructive techniques.

Many reconstructive techniques are used like autologous bone graft, local flaps, free flaps with microsurgical technique, alloplastic materials, bone substitutes and tissue engeneering ${ }^{3-6,10-12}$.

The bone graft is the most used procedure because it is autologous, has no rejection, but it has variable absorption rate at the post operative that may interferes at the final result. Besides, it leads to a donor site morbidity ${ }^{2,5,11,13-18}$.

The temporoparietal fascia flap has demonstrated its adaptability to various reconstructive defects. It is a thin, pliable and resistant coverage to cartilage or osseous tissue and has an important blood supply by the superficial temporal vessels. It has a vascular pedicle and its length allows the flap to reach the ipsilateral defects of the orbitomaxillary region, oral cavity and mandible ${ }^{19}$.

Free flaps are used in difficult reconstructions. They provide reliable, well-vascularized soft tissue and less tissue absorption. However, its complications like arterial or venous thrombosis can lead to a total flap necrosis. Besides, it demands a proper medical team trained on microsurgery technique and special surgical tools $2,3,7,14,16,17,20$.

Alloplastic materials such as titanium, polymers, porous ceramics, hydroxyapatite, collagen sponges or hydrogels can also be used in reconstructive procedures, but there are risks like infection, they do not fully osseointegrate, can become unstable with cranial growth, leads to inflammatory response as a foreign body reaction and may occur extrusion ${ }^{10,21-24}$

Recent advances in tissue-engineering techniques have enabled new procedures to be developed for bone regeneration, and these procedures have the potential to improve on the present clinical strategies. Mesenchymal stem cells were differentiated into connective and mesenchymal tissue by Caplan ${ }^{26}$ and Pittenger et $a l .{ }^{27}$. These cells neoformation and regeneration capacity, special in craniofacial structures are natural. The adult mesenchymal cells derived from bone marrow, subcutaneous tissue, muscle, dental pulp, synovia and umbilical cord are potential donor for cellular therapy. The mesenchymal stem cell is multipotent and differentiates into osteoblasts, chondrocytes, adipocytes and myocytes ${ }^{2,3,6,11,25-30}$.

However, the tissue-engineering techniques demand a specific laboratory, materials and prepared professional team.

It was imagined a galea and periosteum flap with a vascular pedicle and filled with bone fragments, which could be used at osseous facial deformities with a few donor area morbidity.

\section{Methods}

The experimental study was performed from June 2010 to March 2012, at the Experimental Surgery Laboratory of Surgery and Orthopedic Department, Botucatu Medical School with previous approval of the Animal Ethics Committee of Botucatu Medical School, UNESP.

Forty male, Norfolk rabbits of 70 days of life with $1730 \mathrm{~g}$ to $3915 \mathrm{~g}$ (mean $2655.75 \mathrm{~g} \pm 179.29$ ), were divided into two groups. Control Group (CG), with ten animals, had a galea and periosteum cylinder flap done at the right side of calvaria and fixed at the frontal residual periosteum (Figure 1).

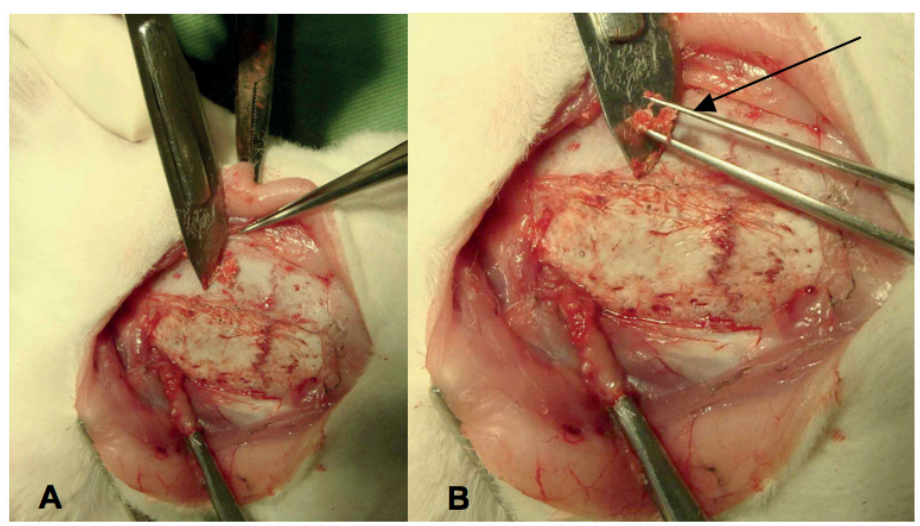

FIGURE 1 - A. Galea and periosteum dissection. B. Flap dissected. C. Cylinder confection.

The treated Group (TG), with 30 animals, had the same 
flap done and filled with fragments of bone harvested with an $\mathrm{n}^{\circ}$ 23 surgical blade, from the other side of the cortical calvarial bone (Figure 2). The flap was fixed at the same place of the other group. All animals had venous anesthesia with Ketamina 10\% - 10mg/kg $\left(\right.$ Dopalen $^{\circledR}$ ) and Xilazina $2 \%$ - 3mg/kg $\left(\right.$ Anasedan $\left.^{\circledR}\right)$.

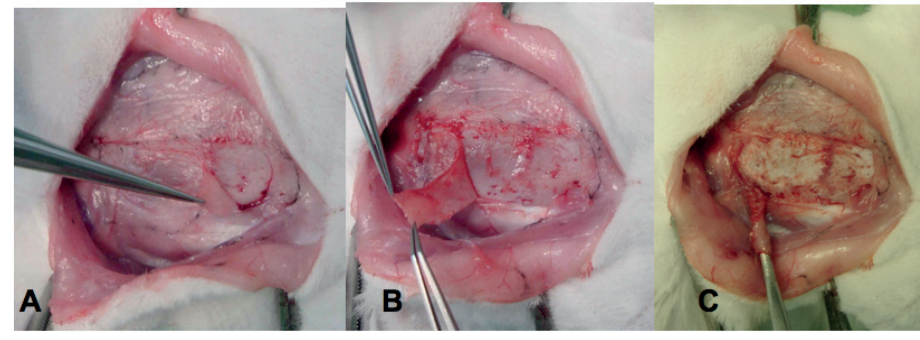

FIGURE 2 - A. Galea and periosteum cylinder confection and bone fragments harvested with an $n^{\circ} 23$ surgical blade. B. Bone dust confection.

After 30 and 60 days post operative all animals were submitted to cranial radiographic exams in two different positions, dorsoventral and lateral views, and evaluated by three different examiners, all plastic surgeons. The radiographies were compared to a normal one of an animal without any intervention, and evaluated any radiopaque image at the right side of the calvaria (Figures 3 and 4).
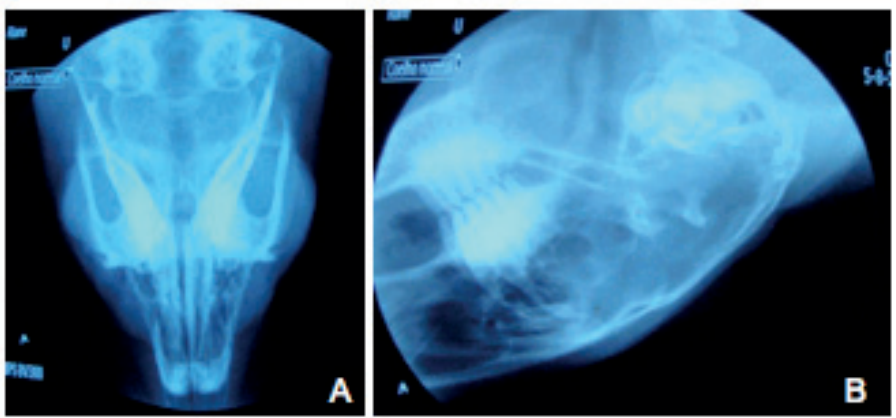

FIGURE 3 - A. Normal dorsoventral radiography. B. Lateral radiography of a normal animal.

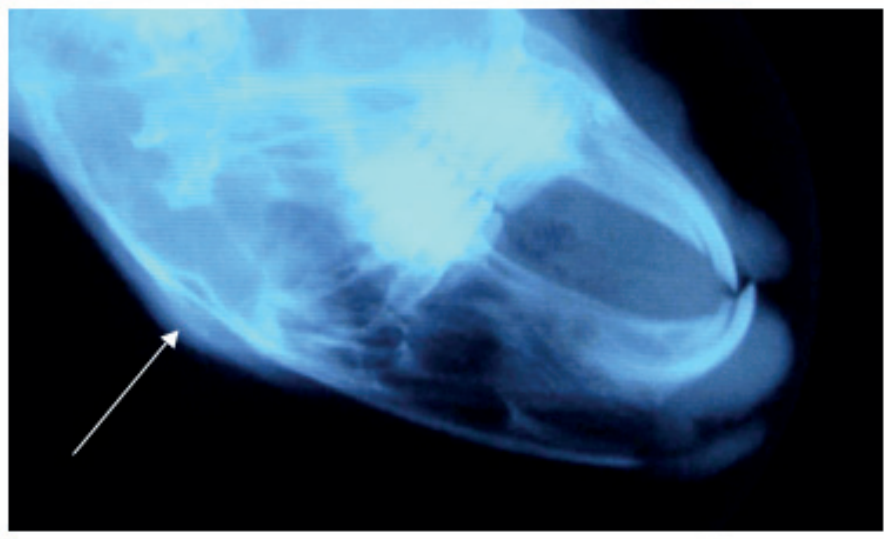

FIGURE 4 - Radiopaque image at cranial calvarial place considered as positive (white arrow), animal $\mathrm{n}^{\mathrm{o}} 05$
After this period, the animals were submitted to surgical procedure to evaluate the flap, if it was bleeding or had some material inside it. After that they were killed with venous anesthesia of Ketamina $10 \%$ - 80mg/kg (Dopalen ${ }^{\circledR}$ ) e Xilazina $2 \%$ - 30mg/kg (Anasedan $\left.{ }^{\circledR}\right)$.

The flap was ressected and sent to histological analysis, stained with hematoxylin and eosin and Masson trichrome. The analysis was done with Leica DMLS microscope. A cellular qualitative analysis was done and the area and perimeter of the formed bone was measured.

The statistical analysis used chi-square tests and, when necessary, Fischer test. To compare the animal weight and bone formation, it was used logistic regression. To evaluate the examiners analysis was used the index of coincidence (Kappa) and ANOVA test was used to compare the area and perimeter values. It was considered $\mathrm{p}<0.05$. The analysis was done in S.A.S 9.3 software for Windows.

\section{Results}

All animals were submitted to surgical procedures and only one from $\mathrm{TG}$, died at the anesthesia for the $30^{\text {th }}$ day radiography.

The animal's initial weight at CG was $2102 \mathrm{~g}$ to $2715 \mathrm{~g}$, mean 2409.30g ( \pm 179.29 ), and at TG was $1850 \mathrm{~g}$ to $3915 \mathrm{~g}$, mean $2737.90 \mathrm{~g}( \pm 521.63)$. There was no statistical difference between the values $(\mathrm{p}=0.0599)$.

Thirty-nine rabbits had a radiographic exam at 30 days postoperative. The analysis had an important variation between the examiners. Control Group had from one animal (10\%) to $90 \%$ of radiopacity at the lateral exam (Table 1). The examiner 1 and 2 , and examiner 1 and 3 had low coincidence (kappa -0.02). Examiner 2 and 3 had high coincidence (kappa - 1.0). It suggests bone formation.

TABLE 1 - Radiography analysis at 30 days postoperative of Control Group. Yes- radiopaque image at right calvarial side. No- Any radiopaque image at right calvarial side.

\begin{tabular}{cccc}
\hline Rabbits & Examiner 1 & Examiner 2 & Examiner 3 \\
\hline 31 & no & yes & yes \\
32 & no & no & no \\
33 & no & yes & yes \\
34 & no & yes & yes \\
35 & no & yes & yes \\
36 & yes & yes & yes \\
37 & no & yes & yes \\
38 & no & yes & yes \\
39 & no & yes & yes \\
40 & no & yes & yes
\end{tabular}


At 60 days radiographies, three animals $(30 \%)$ to 10 $(100 \%)$ had the same image at the lateral exam (Table 2). The examiner 1 and 2, and examiner 1 and 3 had low coincidence (kappa - 0.11). Examiner 2 and 3 had high coincidence (kappa 1.0). No image was identified at dorsoventral view.

TABLE 2 - Radiopacity at lateral view at $60^{\text {th }}$ day x-ray of Control Group animals. Yes- radiopaque image at right calvarial side. No- Any radiopaque image at right calvarial side.

\begin{tabular}{cccc}
\hline Rabbits & Examiner 1 & Examiner 2 & Examiner 3 \\
\hline 31 & yes & yes & yes \\
32 & no & yes & yes \\
33 & yes & yes & yes \\
34 & no & yes & yes \\
35 & no & yes & yes \\
36 & no & yes & yes \\
37 & no & yes & yes \\
38 & yes & yes & yes \\
39 & no & yes & yes \\
40 & no & yes & yes
\end{tabular}

In Treated Group, $34.48 \%, 82.76 \%$ and $86.20 \%$ of the animals presented radiopacity at 30 days (Table 3 ). The coincidence of examiner 1 and 2, and 1 and 3, was low (kappa-0.19 and 0.15). The coincidence of examiner 2 and 3 was high (kappa - 0.86).

TABLE 3 - Radiography analysis at 30 days postoperative of Treated Group. Yes- radiopaque image at right calvarial side. No- Any radiopaque image at right calvarial side.

\begin{tabular}{cccc}
\hline Rabbits & Examiner 1 & Examiner 2 & Examiner 3 \\
\hline 1 & no & yes & yes \\
2 & yes & yes & yes \\
3 & no & yes & yes \\
4 & no & no & no \\
5 & yes & yes & yes \\
6 & no & no & no \\
7 & no & no & no \\
8 & no & yes & yes \\
10 & yes & yes & yes \\
11 & no & yes & yes \\
12 & no & yes & yes \\
13 & yes & yes & yes \\
14 & no & yes & yes \\
15 & yes & yes & yes \\
16 & yes & yes & yes \\
17 & no & yes & yes \\
18 & no & yes & yes \\
19 & no & yes & yes \\
20 & no & no & yes \\
21 & no & yes & yes \\
22 & no & yes & yes \\
23 & yes & yes & yes \\
24 & yes & yes & yes \\
25 & no & yes & yes \\
26 & no & yes & yes \\
27 & yes & yes & yes \\
28 & yes & yes & yes \\
29 & no & yes & yes \\
30 & no & no & no \\
& & &
\end{tabular}

At $60^{\text {th }}$ days radiography, $72.41 \%, 89.65 \%$ e $93.10 \%$ of the animals had radiopacity image, all at the same lateral incidence (Table 4). The coincidence of examiner 1 and 3, was low (kappa$0.10), 1$ and 2 was considerable (kappa - 0.25) and the coincidence of examiner 2 and 3 was substantial (kappa -0.78). No image was identified at dorsoventral view.

TABLE 4 - Radiopacity at lateral view in $60^{\text {th }}$ day x-ray of Treated Group animals. Yes- radiopaque image at right calvarial side. No- Any radiopaque image at right calvarial side.

\begin{tabular}{cccc}
\hline Rabbits & Examiner 1 & Examiner 2 & Examiner 3 \\
\hline 1 & yes & yes & yes \\
2 & yes & no & no \\
3 & yes & yes & yes \\
4 & yes & yes & yes \\
5 & yes & yes & yes \\
6 & yes & yes & yes \\
7 & no & yes & yes \\
8 & yes & yes & yes \\
10 & yes & yes & yes \\
11 & no & yes & yes \\
12 & yes & yes & yes \\
13 & no & no & no \\
14 & no & yes & yes \\
15 & yes & yes & yes \\
16 & yes & yes & yes \\
17 & no & no & yes \\
18 & no & yes & yes \\
19 & no & yes & yes \\
20 & yes & yes & yes \\
21 & yes & yes & yes \\
22 & yes & yes & yes \\
23 & no & yes & yes \\
24 & yes & yes & yes \\
25 & yes & yes & yes \\
26 & yes & yes & yes \\
27 & yes & yes & yes \\
28 & yes & yes & yes \\
29 & yes & yes & yes \\
30 & yes & yes & yes \\
& & & \\
& & & \\
& & &
\end{tabular}

There was no significant difference of bone formation between the groups at 30 days $(p=0.2282, p=1.0000, p=1.0000$ ).

After 60 days, the lateral radiographic images demonstrated significant higher rates of radiopacity at TG $(p=0.0266)$ for only one examiner. The other two examiners had no statistical difference between 30 and 60 days radiographies $(\mathrm{p}=0.5558, \mathrm{p}=1.0000)$.

At the 60 days surgical procedure, all animals from both groups demonstrated good vascularized flaps and no tissue absorption, which suggests good vascular perfusion.

Eleven flaps, from the total thirty-nine animals, demonstrated a yellow tissue inside them; ten were from TG and one from CG. It was thin and spiky in eight and soft and irregular in three of them. The one from CG was soft and irregular (Figures 5 and 6). 

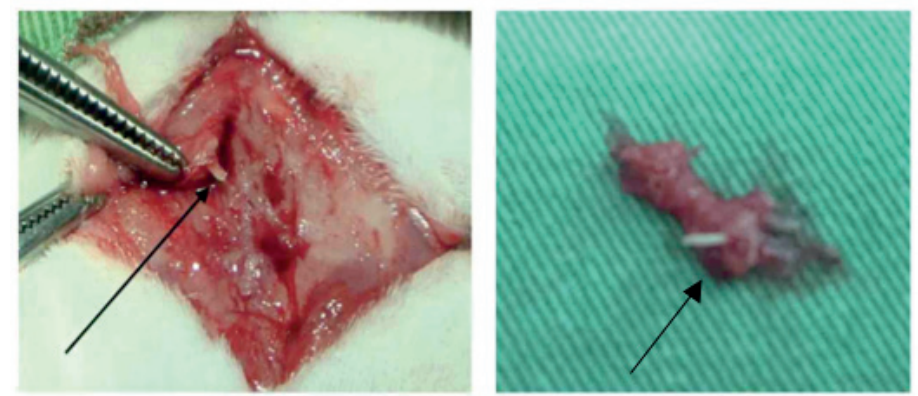

FIGURE 5 - Macroscopic image of a spiky tissue formation inside the flap.
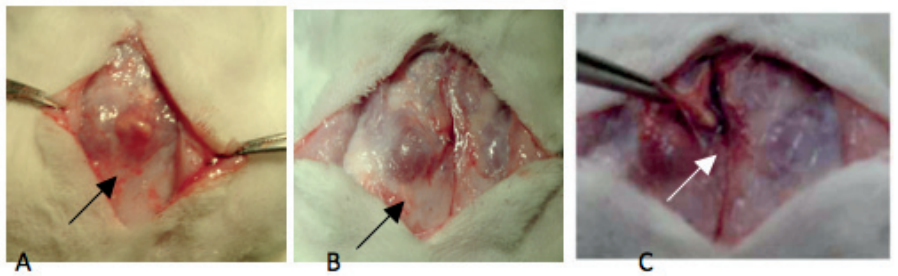

FIGURE 6 - Macroscopic image of a yellow and irregular tissue inside the flaps of animal 19 (A) and 26 (B, C).

The histological analysis of CG demonstrated bone image with an eosinophilic material, osteblasts and fibroblasts in five samples $(50 \%)$. The bone aspect was irregular and trabecular with osteoblast proliferation around it (Figure 7).

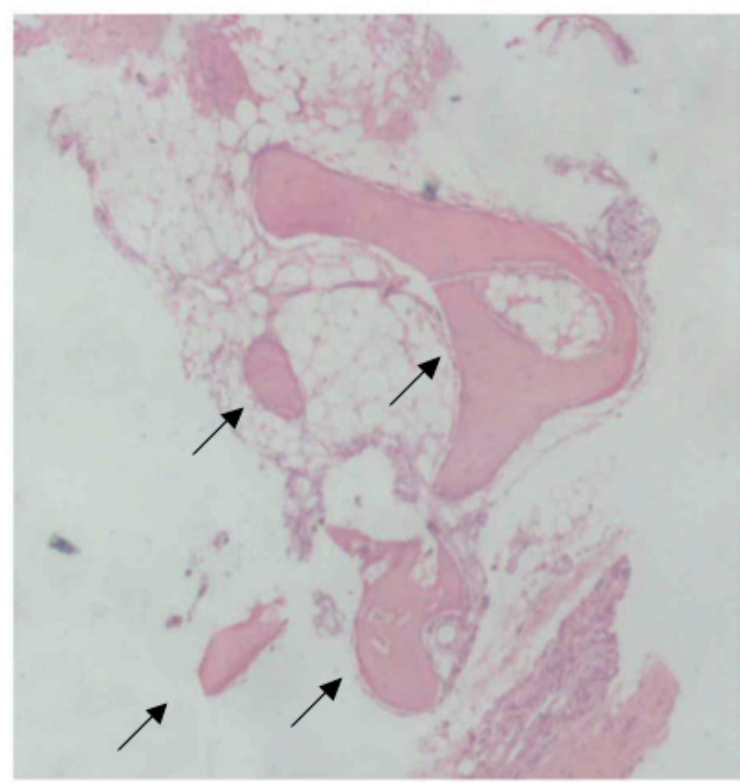

FIGURE 7 - Histological analysis of animal $n^{\circ} 40$ (original magnification 2,5x), from Control Group, with an irregular and trabecular bone neoformation.

At TG histological analysis, twenty samples (68.97\%) had eosinophilic material with osteoblasts in more organized and regular form. Four images (20\%) had vascular formation inside it (Figure 8).

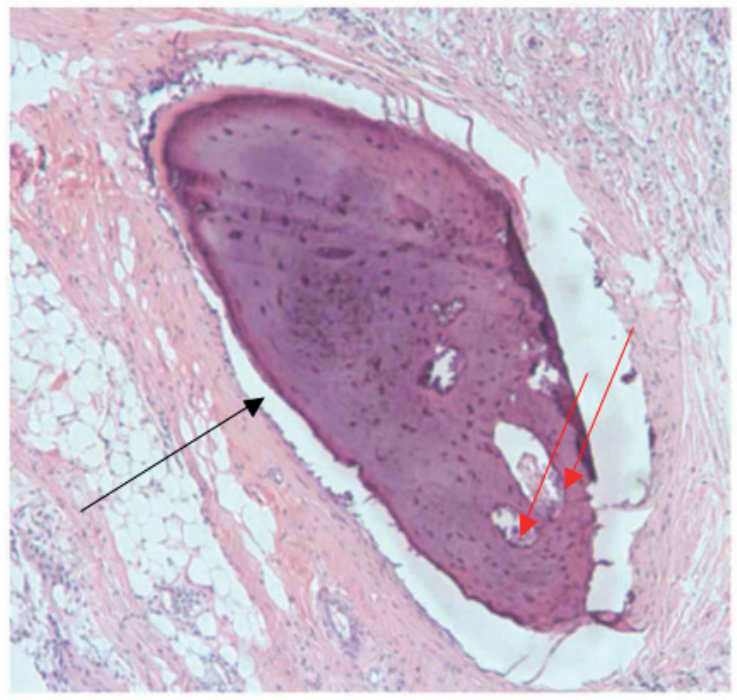

FIGURE 8 - Animal $\mathrm{n}^{\circ}$ 19, from Treated Group (original magnification $2,5 \mathrm{x}$ ), with a regular bone formation (black arrow) and vascular formation inside it (red arrow).

However, bone neoformation had no significant difference between the two groups ( $\mathrm{p}=0.4459)$.

The osseus image area and perimeter were measured in all histological samples. At CG, the area was 2.447 to 321.751 $\mathrm{mm}^{2}\left(\right.$ mean $\left.=90.512 \mathrm{~mm}^{2}\right)$ and perimeter was 0.225 to $5.04 \mathrm{~mm}$ (mean $=1.82 \mathrm{~mm}$ ). In TG, the area was 20.604 to $3041.709 \mathrm{~mm}^{2}$ $\left(\right.$ mean $\left.=450.419 \mathrm{~mm}^{2}\right)$ and the perimeter was 0.79 to $18.448 \mathrm{~mm}$ (mean=3.59 mm). There was no significant difference between the group's values $(\mathrm{p}=0.3979)$.

\section{Discussion}

The choice to use rabbits as experimental animals was made because it has an adequate calvaria size, larger than rats and it has a vascularized tissue by the temporal artery and vein. The rabbit has been used as experimental animal to bone defects and cranial reconstruction studies ${ }^{24,31}$.

The morcelized bone graft used into vascularized flaps demonstrated that the osseous cells and proteins from growth factor family are necessary to progenitor cells induction of the periosteum. It is considered an ideal biomaterial to bone neoformation because it is a complement of growth factors stored in the noncalcified matrix of morcellized bone graft, such as bone morphogenetic proteins and proteins of the fibroblast growth factor family, induce progenitor cells within the periosteum to an osteogenic phenotype and result in new bone formation within the chambers $^{32,33}$.

For this reason, it was used bone dust, fragments of the 
cortical calvarial bone, because it has osseous cells and essential proteins to bone formation induction, and minimum donor site morbidity.

The vascularized calvarial flaps are better than bone grafts because it has less absorption, better osseous integration and less infection rate ri,34. $^{17}$.

The periosteum is a vascularized membrane that covers the bone and is important at osseous healing. Studies demonstrated that the periosteum induces cartilage and bone formation, depending on the oxygen tension and protein levels. The fibroblasts from the outer layer of the periosteum and the osteoblasts from the inner layer provide a collagen matrix important at the healing process $^{9,32,33}$.

The choice to use periosteum and calvaria flap was done because of the temporal vascular pedicle, which is flexible, can reach local areas and can be shaped in different forms, besides the regeneration capacity of the periosteum.

Macroscopic analysis demonstrated $100 \%$ vascularized tissue, no absorption of the flap and images inside the flap that suggested bone neoformation, one at CG $(10 \%)$ and ten at TG $(34.48 \%)$.

The radiographic results suggest osseous formation at the top of the calvaria where the flap was made, in lateral position images. At the dorsoventral view, there was no suggestive image of neoformed bone, may be because the osseous superposition of the rabbit calvaria that makes it difficult to differentiate osseous structures.

The histological analysis confirmed bone formation in both groups. However, the structure of this neoformed osseous tissue was different. In CG, 50\% of the samples had irregular eosinofilic images with osteoblasts, which characterized a trabecular bone. And in TG, the eosinofilic image was organized, with regular borders and osteoblasts, characteristics of a more mature bone formation.

The area and perimeter had a large variety of values and did not demonstrate statistical difference between the groups. For this reason the bone was not considered by quantity but it was considered by quality and histological differences.

At this study, it was possible to demonstrate bone formation in vascularized flaps of galea and periosteum of rabbitt's calvaria and it was possible to differ tissue formation in two kinds of surgical techniques. However, the real viability analysis of this galea and periosteum flap filled with bone fragments could not be proved and demands more studies to reach a real conclusion.

\section{Conclusion}

This study demonstrated osseous formation in both groups, with and without bone fragments.

\section{References}

1. Baumeister S, Peek A, Friedman A, Levin L S, Marcus J R. Management of postneurosurgical bone flap loss caused by infection. Plast Reconstr Surg. 2008;122(6):195-208.

2. Casabona F, Martin I, Muraglia A, Berrino P, Santi P, Cancedda R, Quarto R. Prefabricated engineered bone flaps: an experimental model of tissue reconstruction in plastic surgery. Plast Reconstr Surg. 1998;101(3):577-81.

3. Alam I, Asahina I, Seto I, Oda M, Enomoto S. Prefabricated vascularized bone flap: A tissue transformation technique for bone reconstruction. Plast Reconstr Surg. 2001;108(4):952-8. Corrigido de acordo com o PubMed

4. Goiato MC, Santos, DM, Haddad MF, Pesqueira AA, Carvalho Dekon SF, Zavanelli AC. Most frequent tumors in maxillofacial area rehabilitated through surgical reconstruction and prostheses. J Craniofac Surg. 2010;21(2):396-9.

5. Hara T, Santos CA, Farias A, Costa MJM, Cruz RJLC. Cranioplastia: parietal versus prótese customizada. Rev Bras Cir Plast. 2011;26(1):32-6.

6. Mao JJ, Giannobile WV, Helms JA, Hollister SJ, Krebsbach PH, Longaker MT, Shi S. Craniofacial tissue engineering by stem cells. J Dent Res. 2006;85(11):966-79.

7. Yano T, Tanaka K, Kishimoto S, Iida H, Okazaki M. Review of skull base reconstruction using locoregional flaps and free flaps in children and adolescents. Skull Base. 2011;21:359-64.

8. Posnick JC. Treacher Collins syndrome: Evaluation and treatment. In Craniofacial and maxillofacial surgery in children and young adults. 1ed. Philadelphia: Saunders; 2000.

9. Soltan M, Smiler D, Soltan C. The inverted periosteal flap: a source of stem cell enhacing bone regeneration. Implant Dent. 2009;18(5):373-9.

10. Kumar AR, Bradley JP, Harshbarger R, Stevens F, Bell R, Moores L, Armonda R. Warfare-related craniectomy defect reconstruction: early success using custom alloplast implants. Plast Reconstr Surg. 2011;127(3):1279-87.

11. Chang SH, Tung KY, Wang YJ, Tsao YP, Ni TS, Liu HK. Fabrication of vascularized bone grafts of predetermined shape with hydroxyapatite-collagen gel beads and autogenous mesenchymal stem cell composites. Plast Reconstr Surg. 2010;125(5):1393-402.

12. Laureano Filho JR, Castelo Branco BL, Andrade ESS, Barbosa JRA. Comparação histológica entre o osso desmineralizado e polímero de mamona sobre a regeneração óssea. Rev Bras Otorrinolaringol. 2007;73(2):186-92.

13. Netscher, DT, Stal S, Shenaq S. Management of residual cranial vault deformities. Clin Plast Surg. 1992;19:301-13. Corrigido de acordo com o PubMed

14. Grant GA, Jolley M, Ellenbogen RG, Roberts TS, Gruss JR, Loeser JD. Failure of autologous bone-assisted cranioplasty following decompressive craniectomy in children and adolescents. J Neurosurg. 2004;100(2):163-8.

15. Park HK, Dujovny M, Agner C, Diaz FG. Biomechanical properties of calvarium prosthesis. Neurol Res. 2001;23(2-3):267-76.

16. Gosain AK, McCarthy JG, Staffenberg D, Glat PM, Simmons DJ. The histomorphologic changes in vascularized bone transfers and their interrelationship with the recipient sites: a 1-year study. Plast 
Reconstr Surg. 1996;97(5):1001-13.

17. Vögelin E, Jones NF, Lieberman JR, Baker JM, Tsingotjidou AS, Brekke JH. Prefabrication of bone by use of a vascularized periosteal flap and bone morphogenetic protein. Plast Reconstr Surg. 2002;109(1):190-8.

18. Gosain AK, Song L, Santoro, TD, Amarante MTJ, Simmons DJ. Long-term remodeling of vascularized and nonvascularized onlay bone grafts: a macroscopic and microscopic analysis. Plast Reconstr Surg. 1999;103(5):1443-50.

19. Jaquet Y, Higgins K, Enepekides D. The temporoparietal fascia flap: a versatile tool in head and neck reconstruction. Curr Opin Otolaryngol Head Neck Surg. 2011;19(4):235-41.

20. Aspoas AR, Wilson GR, McLean NR, Mendelow AD, Crawford PJ. Microvascular reconstruction of complex craniofacial defects. Ann R Coll Surg Engl. 1997;79:278-83.

21. Saska S, Hochuli-Vieira E, Pereira Filho VA, Gabrielli MAC, Oliveira CF, Cancian DCJ. Implantes de polietileno poroso em calota de coelho. Análise histológica comparativa. Rev Cir Traumatol Buco-Maxilofac. 2007;7(3):49-58.

22. Schofer MD, Roessler PP, Schaefer J, Theisen C, Schlimme S, Heverhagen JT, Voelker M, Dersch R, Agarwal S, FuchsWinkelmann S, Paletta JRJ. Electrospun PLLA nanofiber scaffolds and their use in combination with BMP-2 for reconstruction of bone defects. PloS One. 2011;6(9):e25462. Corrigido de acordo com o PubMed

23. Agrawal A, Baisakhiya N, Bhola N. Split calvarial graft to repair the large frontal bone defect. J Maxilofac Oral Surg. 2010;9(2):166-9.

24. Hassanein AH, Arany PR, Couto RA, Clune JE, Glowacki J, Rogers GF, Mulliken JB, Greene AK. Cranial particulate bone graft ossifies calvarial defects by osteogenesis. Plast Reconstr Surg. 2012;129(5):796e-802e.

25. Chen Y, Wang G, Zeng L. Adipose tissue or bone marrow, store for purchasing mesenchymal stem cells? Circ J. 2011;75:2060-1. Corrigido de acordo com o PubMed

26. Caplan AI. Mesenchymal stem cells. J Orthop Res. 1991;9:641-50.

27. Pittenger MF, Mackay AM, Beck SC, Jaiswal RK, Douglas R, Mosca JD, Moorman MA, Simonetti DW, Craig S, Marshak DR. Multilineage potential of adult human mesenchymal stem cells. Science. 1999;284(5411):143-7. Corrigido de acordo com o PubMed

28. Orbay H, Tobita M, Mizuno H. Mesenchymal stem cells isolated from adipose and other tissues: basic biological properties and clinical applications. Stem Cells Int. 2012;2012:461718. Corrigido de acordo com o PubMed

29. Hamajima S, Hayashi T, Sato Y, Sasaki K, Kawai T. Osteoanagenesis after transplantation of bone marrow-derived mesenchymal stem cells using polyvinylidene chloride film as a scaffold. Dent Mater J. 2011;30(5):707-16.

30. Wang Y, Han Z, Song Y, Han ZC. Safety of mesenchymal stem cells for clinical application. Stem Cells Int. 2012;2012:1-4.

31. Parro F, Viterbo F, Viterbo BG, Ueda A, Pinca F, Zanini S. Histological and radioisotopical analysis of the skull graft: an experimental study in rabbits. J Craniofac Surg. 1992;3(4):203-6.

32. Brey EM, Cheng MH, Allori A, Atterfield W, Chang DW, Patrick $\mathrm{Jr}$ CW, Miller MJM. Comparison of guided bone formation from periosteum and muscle fascia. Plast Reconstr Surg. 2007;119(4):1216-22.

33. Cheng MH, Brey EM, Ulusal BG, Wei FC. Mandible augmentation for osseointegrated implants using tissue engineering strategies. Plast Reconstr Surg. 2006;118(1):1e-4e.

34. Davison SP, Mesbahi AN, Clemens MW, Picken CA. Vascularized calvarial bona flaps and midface reconstruction. Plast Reconstr Surg. 2008;122(1):10e-18e.

\section{Correspondence:}

Ryane Schmidt Brock

Rua Jandiatuba, 630/sala 227

05716-150 São Paulo - SP Brasil

Tel.: (55 11)99112-3993

Fax: (55 11)3476-3136

rybrock@ig.com.br

Received: October 15, 2012

Review: December 18, 2012

Accepted: January 16, 2013

Conflict of interest: none

Financial source: Sao Paulo Research Foundation (FAPESP)

${ }^{1}$ Research performed at Experimental Surgery Laboratory, Surgery and Orthopedics Department, Medical School of Botucatu, Sao Paulo State University (UNESP), Brazil. Master degree thesis, Postgraduate Program in General Surgery Basis, Medical School of Botucatu, UNESP. Tutor: Prof. Fausto Viterbo. 